\section{B.M.A. Membership}

SIR,-Among the letters and articles critical of the B.M.A., of which there has been a minor spate lately, several have made reference direct or implied to the Association's "failing membership."

The large majority of doctors who make up the Association readily accept fair criticism. Indeed, many of us also accept that part of the raison dêtre of the Association is to act as whipping-boy for the blows of those who seemingly rely on this activity to bolster up their own cause.

Nevertheless, in fairness to our loyal membership, alleged to be failing, may I prewide, and about a quarter of it is overseas. Overseas membership is subject to major fluctuations when Commonwealth Branches of the B.M.A. are wound up and replaced by independent associations. Such a change occurred last year in the cases of New Zealand, Nigeria, and Sierra Leone, and overseas membership diminished as a result by more than 3,000 . In passing, may I say that the B.M.A. welcomes these changes, and in all sent the facts. B.M.A. membership is world-

cases welcomes mutual affiliation with the associations concerned.

It follows that it is the British membership which is the significant factor. In 1967, as the final consequence of a major subscription increase in 1966, British membership fell by $0.15 \%$ or 75 members out of 49,000 . Since 1 January this year there has been a steady increase in membership, reflected in all branches of the profession. Today, in midApril, the net increase over the total 12 months ago is 769 , or $1.5 \%$. Should this trend continue, and past experience shows that this is likely, then by the end of the year the British increase will have substantially, if not fully, offset the loss of overseas members last year.

The Council of the Association is very appreciative of this growing support for the Association, which in round figures represents 7 out of every 10 practising doctors, and, happily, still 6 out of 10 of those who are retired.-I am, etc.,

London W.C.1. $\begin{gathered}\text { RoNALD GIBSON, } \\ \text { Chairman of Council }\end{gathered}$

\section{Size of B.M.A. Committees}

SIR,-Reading your reports of the central discussions on proposed constitutional changes (6 April, Supplement, p. 4) leaves an uncomfortable impression that the Council may be falling into the same sort of error as that other governmental body a few miles south of Tavistock Square, of presenting as measures of choice what in fact are hastily prepared measures dictated by necessity. If, for economy's sake, you part with your Rover and take to a Mini you don't have to convince yourself that the Mini is really the better car for your purposes. Yet something very like this is what a majority of the Council is asking us to accept. In effect we are asked to believe that our predecessors were both extravagant and stupid, and that the committees they established over the years were at once oversized and inefficient. We are even invited to agree that these committees were twice (" approximately") as large as they should have been. Is this really likely?

From 40 years' experience of observing committees at work-mostly from the observation post of the secretarial chair-I would say that there is no discernible correlation between the size of a committee and its efficiency in operation. Two committees of equal size can be very different in their speed and efficiency of working. Other things being equal, of course, the smaller committee is likely to reach its conclusions more rapidly than the larger. It does not, however, follow that its conclusions will necessarily be wiser. Indeed, the chances are probably the other way round. But the real point surely is that there is an optimum size for any council or committee, and that this must vary very widely according to the nature and purpose of each. Certainly it is sensible at any time, and especially under economic stress, that an association such as ours should take steps to see that its committees are as near as may be to the optimum size. Unselective chopping will not achieve this. A gardener who prunes his fruit trees by hacking out half their branches is not likely to get good results. If we are compelled by economic necessity to prune below the optimum at least let us recognize what we are doing.

It is not clear from the reports whether other ways of achieving the desired economies have been fully explored. There are two features which distinguish an efficient organization. These are that what it does it does efficiently and economically, and that it does not dissipate resources on doing (however efficiently) things which, though in themselves desirable, are not necessary for the achievement of its objects. It seems to me at least possible that we are in our present difficulties not so much because we have neglected the first point as because we have paid too little attention to the second. Dr. J. G. M. Hamilton's contention (13 April, p. 121), which I think is justified, that the Representative Body has "generated work and expense" seems to lend support to this view. This, however, is not an argument for dispensing with the Representative Body. Rather it is an argument for the Association as a whole, guided by Council, to adopt a much more clearly defined policy on the use of its resources based on a realistic assessment of cost-benefit. In broad terms, I believe this should be to concentrate, meantime at any rate, on those things which the Association is specially suited to do, things which no other body or group can do so effectively. Among these the most obvious are in the medico-political field. Whether we like it or not, the National Health Service is for most of the profession the central fact of medical life in this country. What happens to the Health Service is therefore of the utmost British doctors now and in the future. That there are going to be changes in the next few years is certain. What form they take, and the extent to which they will be influenced, as they ought to be, by the conimportance, directly or indirectly, to all sensus of medical opinion, will depend more than anything else on the action of the B.M.A. at this time.

In view of this it seems a pity that the Council did not see fit to include in its Annual Report the interim report of the Advisory Planning Panel on the History and Financial Aspects of the Health Service, and that the Scottish Council has been refused the $£ 300$ needed to print and circulate to members in Scotland, for discussion, the account of the work of its National Health Service Review Committee over a period of 15 years. - I am, etc.,

Gorebridge,
Midlothian.

EDWARD WALKER

\section{Visiting in General Practice}

SIR,-As a general practitioner recently retired after over 30 years in a busy threeman practice in a large industrial city in the Midlands, I was appalled on reading the article "Visiting - Falling Work-load in General Practice" by Dr. G. N. Marsh (9 March, p. 633). How commercialized can medical practice become! May I take some of his points in favour of cutting down home visiting to a minimum ?

He started in 1960 to visit at the same rate as his predecessor, a highly esteemed senior partner, to establish himself as a doctor " as keenly interested in the welfare of the patients" as he had been, but goes on to infer that the older doctors in the days of private practice over-visited purely for financial gain.

Nothing could be further from the truth. In those days, and I hope in the majority of cases today, they were dedicated to medicine as a calling, and put the welfare of their patients first, treating them as individuals, and not simply as clinical cases of one disease or another. Their financial reward was a secondary consideration. The chronic elderly patients visited once a month looked forward to the doctor's visit, and it was a great satisfaction to see how much they appreciated it. Now he would have them all struggle along to the surgery, to save 10 to 15 minutes of his time, and only visit them in an exacerbation, because then they are far more interesting.

He says only one visit is necessary in an illness unless the patient reports that the "expected improvement" has not taken place. Does he leave the mother of a child with, say, bronchopneumonia to know whether the expected improvement is taking place ? Perhaps, of course, he sends all his pneumonias to hospital. $\mathrm{He}$ recommends patients to look on the visiting doctor as a person rarely needed in the normal course of events. But in conclusion says " there is no doubt seeing a patient in his own home often provides vital and valuable information about him and his illnesses." What a contradiction! -I am, etc.

Aberdeen.

J. COOPER.

SIR,-Reading Dr. G. N. Marsh's interesting article on domiciliary visiting in general practice (9 March, p. 633) prompts me to record my total visiting figures over the 12 years 1956-67 (48-week working year) to illustrate how the work-load varies from practice to practice and from year to year. 
It should be pointed out that the list-sizes represent half the totals for a two-man partnership, it being assumed that the visits were shared approximately equally. The locality is urban district. The area can be visualized diagrammatically as a semi-circle whose radius is 3 miles $(5 \mathrm{~km}$.), the surgery being at the centre-point of the circle. The numbers of visits included attendances at confinements at two general-practitioner maternity units-ome $6 \frac{1}{2}$ miles $(10 \mathrm{~km}$.), and the other 8 miles $(13 \mathrm{~km}$.) away (in the same geographical direction from the surgery as the main practice area). Also included were visits from time to time to a chronic sick unit and an aged persons' home, and these were usually recorded as one "visit," though often several patients were seen. The graph also includes as "visits" (approximately once a week) general anaesthetic sessions at a dental surgery. The relatively high peaks in 1957 and 1959 are attributable to influenza epidemics (in October 1957 and February 1959). The general falling off since 1963 is due to the help of assistants, and the further fall since 1966 to the advent of a new principal.

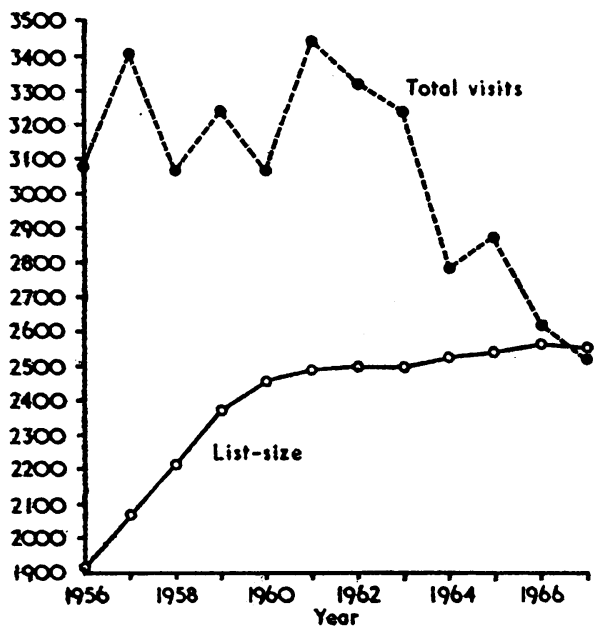

It is anticipated, as it is by Dr. Marsh, that a further reduction in visiting patients' homes will be achieved by deliberate planning.-I am, etc.,

Chertsey,
Surrey.

D. G. Davidson.

\section{Real Reasons for Emigrating}

SrR,-Why is the Australian general practitioner more content than his N.H.S. counterpart? He enjoys the respect of his patients to a greater extent than the English general practitioner. Unlike Dr. E. C. Gamble (3 February, p. 320) I do not relate this to payment through the nose. Dr. P. B. Forbes's comment (17 February, p. 450) that respect is indeed engendered by professional competence is apt. It is not suggested that the average Australian is more competent than the average Englishman; the crux of the matter is that over here one can exercise the skills for which one trained.

As a general practitioner over here I perform complicated obstetrical manœuvres and do major gynaecological surgery. In England it would be virtually impossible to combine general practice with a specialty. We assist most surgeons who operate on our patients, and are responsible for much of the postoperative care. Incidentally, a further reason for emigration is possibly the reluctance of consultants to pay their registrar for assistance with private patients even when off duty. The terms of service make no reference to this disquieting feature of some residents' commitments. The spontaneous promise of payment cannot be enforced, as I know to my cost. Minor surgical procedures are well within the ability of all doctors. In Australia the bulk of practitioners perform them. In England the majority were referred either to the casualty department or nearest surgical outpatient department. Best of all we have the privilege of responsibility for our own patients' care in hospital. The ham-handed operator is no more frequently encountered in the Antipodes than in the United Kingdom.

There is a direct relationship between the amount of work done and income. A financial incentive to work harder is no bar to good medicine; on the contrary. Many of our patients are expatriates from the United Kingdom. Much to my surprise they prefer the system over here. The family-doctor concept is still a real entity in Australia. Much of the sting of the doctor's bill is taken away by "hospital benefits"-in most cases $80 \%$ of the fee paid is returned to the patient. In cases of hardship an account is reduced or waived. Few complaints are heard about medical costs.

The average practitioner over here enjoys a better climate, a higher standard of living, a healthier doctor-patient relationship, better conditions under which to work, and most of all the work itself. In view of the above, I submit that continued medical emigration from the United Kingdom to Australia is ineluctable.- I am, etc.

$$
\begin{aligned}
& \text { Mordialloc, } \\
& \text { Victoria, Australia. }
\end{aligned}
$$

$$
\text { Matthew J. O'Neill. }
$$

\section{Recommendations of the Royal Commission}

SIR,-It seems from your report (13 April, p. 109) that the Royal Commission on Medical Education ${ }^{1}$ has not considered one factor which will upset all their calculations. The question is, to what extent is a medical training necessary to the handling of psychological problems ? In practice about a third of the time and energy of a general practitioner is spent on such problems, varying greatly with the interest he shows. At what point should he refer them, and to whom? To what extent should drugs be used, and to what extent talk? Should we be training thousands of extra doctors or thousands of extra psychotherapists ? It makes a lot of difference to the cost and to the results. I think myself that the bulk of psychological and social problems will be best delegated to therapists with the appropriate education and experience, working with and equal in status to doctors. The difficulty in planning such training is that we do not know how big the real demand is ; what present needs are unrecognized; what new demands are likely to appear; and how people with a problem choose which particular adviser to approach, or when they give it up as hopeless.-I am, etc.,

London N.3.

J. R. Scotr.

REFERENCB

Royal Commission on Medical Education, 1968, Cmnd. 3569. H.M.S.O., London.

\section{Verification of Qualifications}

SIR,-In the light of the statement made by the General Medical Council calling on hospital authorities to verify qualifications (16 March, Sapplement, p. 78), might I suggest that every practitioner in medicine and surgery should be granted a visa bearing his or her photograph, signature, qualifications with date of registration, and country of issue. This document should be endorsed by the Medical Registrar every three years.

This would bring the profession up to date, avoiding all the unpleasant sequelae associated with employment of bogus practitioners. - I am, etc.,

E. A. P. Sutherland-Rawlings. London W.2.

\section{Points from Letters}

\section{Hypothermia in the Aged}

Dr. J. A. J. MACLEOD (Lewisham Hospital, London S.E.13) writes : During December 1967 most of the emergency medical admissions to this hospital over the age of 65 had their rectal temperature measured on arrival in the casualty department, using a low-reading thermometer for two minutes. Of those whose temperature was properly recorded by a sister or a staff nurse 80 patients were over the age of 65 , and of them 18 showed a rectal temperature of $96^{\circ} \mathrm{F}$. $\left(35.5^{\circ}\right.$ C.) or below.

Many old people living alone will admit to stoking up a dwindling fire on the day that they expect a visit from their conscientious relative, general practitioner, district nurse, or health visitor, thus creating a false impression of homely warmth. Would it not therefore be a worthwhile investment to provide all elderly people with a low-reading thermometer and a simple card of instruction for the measurement of oral temperature? The temperature could be recorded by any regular visitor. This would go a long way towards the detection of hypothermia and would be the first step in the prevention of the associated morbidity.

\section{Medicine and Mass Media}

Dr. M. Glass (Cape Town, S. Africa) writes: Besides answering the critics of the heart transplant operation, Mr. I. G. Sacks's timely hardhitting riposte (2 March, p. 577) "revivified the bloodless shadows of the past." Listening with my eyes I could hear the bitterness and disillusionment of Vesalius (1514-64) ${ }^{1}$ as he ran the gauntlet of "the pestilential creatures who calumniate anyone they discover to know something unknown to them, admitting he is skilled in such things but that he is no physician, as if great diligence in some of the disciplines underlying medicine might detract from the knowledge of medicine. ..." It is a pleasure to give my support to Mr. Sacks's spirited and loyal support of Professor Barnard's innovation.

\section{REPERENCB}

1 O'Malley, C. D. Andreas Vesalius of Brussels, Ma64 p. 218-219. Berkeley and Los Angeles. 